\section{(2) OPEN ACCESS}

\title{
Adult liver transplantation: A UK clinical guideline - part 1: pre- operation
}

\author{
Charles Millson (D) ,' Aisling Considine, ${ }^{2}$ Matthew E Cramp, ${ }^{3}$ \\ Andrew Holt, ${ }^{4}$ Stefan Hubscher, ${ }^{5}$ John Hutchinson, ${ }^{6}$ Kate Jones, ${ }^{7}$ \\ Joanna Leithead, ${ }^{8}$ Steven Masson, ${ }^{9}$ Krish Menon, ${ }^{10}$ Darius Mirza, ${ }^{11}$ \\ James Neuberger, ${ }^{12}$ Raj Prasad, ${ }^{13}$ Anthony Pratt, ${ }^{14}$ Wendy Prentice, ${ }^{15}$ \\ Liz Shepherd, ${ }^{16}$ Ken Simpson, ${ }^{17}$ Doug Thorburn, ${ }^{18}$ Rachel Westbrook, ${ }^{19}$ \\ Dhiraj Tripathi ${ }^{20}$
}

\begin{abstract}
- Additional material is published online only. To view please visit the journal online (http://dx.doi.org/10.1136/ flgastro-2019-101215).
\end{abstract}

For numbered affiliations see end of article.

\section{Correspondence to}

Dr Charles Millson, Hepatology, York Hospitals NHS Foundation Trust, York YO31 8HE, UK; charlie.millson@btinternet.com

Received 27 February 2019 Revised 7 October 2019 Accepted 9 October 2019 Published Online First 25 February 2020

\section{Check for updates}

(C) Author(s) (or their employer(s)) 2020. Re-use permitted under CC BY-NC. No commercial reuse. See rights and permissions. Published by BMJ.

\section{To cite: Millson C,}

Considine A, Cramp ME, et al. Frontline Gastroenterology 2020;11:375-384.

\begin{abstract}
Liver transplantation is a highly successful treatment for all types of liver failure, some non-liver failure indications and liver cancer. Most referrals come from secondary care. This first part of a two-part guideline outlines who to refer, and how that referral should be made, including patient details and additional issues such as those relevant to alcohol and drug misuse. The process of liver transplant assessment involves the confirmation of the diagnosis and non-reversibility, an evaluation of comorbidities and exclusion of contraindications. Finally, those making it onto the waiting list require monitoring and optimising. Underpinning this process is a need for good communication between patient, their carers, secondary care and the liver transplant service, synchronised by the transplant coordinator. Managing expectation and balancing the uncertainty of organ availability against the inevitable progression of underlying liver disease requires sensitivity and honesty from all healthcare providers and the assessment of palliative care needs is an integral part of this process.
\end{abstract}

\section{INTRODUCTION}

Over just three decades, UK liver transplantation has evolved from the enthusiastic efforts of a few well-intentioned clinicians to a multidisciplinary, closely scrutinised therapy with 1-year survival rates in excess of $90 \% .{ }^{1-3}$ Despite these excellent outcomes, only a small fraction of the increasing numbers of patients dying of end-stage liver disease will be referred to a liver transplant unit (LTU) for this life-saving procedure.
This two-part guideline is specifically aimed at non-specialist clinicians caring for patients with acute and chronic liver disease (CLD). The first part examines:

- Who to refer for liver transplant (LT).

- How to refer for LT.

- The LT Assessment.

- How to manage the patient on the waiting list.

Part 2 explores the post operative care of the LT recipient.

Further reading includes guidelines from BSG (1999), ${ }^{4}$ BASL (2012), ${ }^{5}$ EASL Guidelines for LT $(2015)^{6}$ and acute liver failure $(\mathrm{ALF})^{7}$ and AASLD guideline for LT (2013). ${ }^{8}$

\section{WHO TO REFER FOR LT}

Over $90 \%$ of LTs in the UK are performed for CLD, where a gradual destruction of liver tissue results in the familiar picture of jaundice, ascites, encephalopathy with coagulopathy and hypoalbuminaemia. A smaller number will have $\mathrm{ALF}^{37}$ and an even smaller number are transplanted for a non-failing liver, where there is survival advantage. ${ }^{9}$ This section identifies the reasons, which should prompt either a referral to an LTU or mandate an enquiry.

\section{Acute liver failure}

While there are several ALF definitions, ${ }^{7}$ the critical elements for the purpose of this guideline, are the three cardinal features of encephalopathy, jaundice and coagulopathy appearing in a patient who, less than 6 months ago, had no evidence of advanced liver disease. The challenge for the generalist in an AMU or emergency department 
Table 1 When referral/discussion with the LTU is required for a patient with $\mathrm{ALF}^{7}$

\begin{tabular}{ll}
\hline Paracetamol induced acute liver failure & Non-paracetamol induced acute liver failure \\
\hline Arterial $\mathrm{pH}<7.30$ or $\mathrm{HCO}_{3}<18$ & $\mathrm{pH}<7.30$ or $\mathrm{HCO}_{3}<18 \mathrm{mmol} / \mathrm{I}$ \\
INR $>3.0$ on day two or $>4.0$ thereafter & INR $>1.8$ \\
Oliguria and/or AKI & Oliguria/renal failure or $\mathrm{Na}<130 \mathrm{mmol} / \mathrm{L}$ \\
Altered level of consciousness & Encephalopathy, hypoglycaemia or metabolic acidosis \\
Hypoglycaemia & \\
Elevated arterial lactate ( $>4 \mathrm{mmol} / \mathrm{L})$ unresponsive to fluid $>300 \mathrm{umol} / \mathrm{L}(17.6 \mathrm{mg} / \mathrm{dL})$ \\
\\
resuscitation
\end{tabular}

AKI, acute kidney injury; ALF, acute liver failure; CLF, chronic liver failure; INR, international normalised ratio; LT, liver transplantation; LTU, liver transplant unit.

environment is establishing the diagnosis of severe liver injury quickly and minimising the delay in seeking help. ${ }^{10}$ Early discussions with LTU enable decisions on comorbidities or contraindications to LT (see below) to be addressed before hepatic encephalopathy develops and safe transfer becomes too high-risk.

\section{Causes of ALF}

Despite changes to packaging, paracetamol (acetaminophen) poisoning remains the the most common cause for ALF in the UK. ${ }^{11}$ The next most common cause is non-A-to-E hepatitis, then other drug induced liver injuries (prescribed, herbal and proscribed), viral hepatitis and ischaemic hepatitis. Malignancy (primary or secondary), pregnancy (AFLP/HELLP), vascular (including Budd-Chiari Syndrome) and metabolic disorders are rarer causes.

Alcoholic hepatitis is considered in the CLD section, as is acute on chronic liver failure (AoCLF).

When to consider referral/discussion with the LTU in ALF

Once diagnosed, the ALF patient should be managed in an HDU environment and discussed with a LTU (see table 1). Important details include any history of paracetamol ingestion (timing, frequency, 'staggered'), pregnancy, other drugs (prescribed, herbal or proscribed), comorbidity (mental and physical health), laboratory results (including PT, $\mathrm{pH}$, arterial lactate, glucose, renal function, viral screen, autoantibodies and immunoglobulins) and liver imaging. Ideally, patients are safer transferred before encephalopathy appears, although there is little published guidance covering this important issue.

Table 1 outlines clinical features in paracetamol and non-paracetamol ALF that correlate with poor outcome and mandate referral. Rarely, non-paracetamol ALF, can present with ascites, deep jaundice and even variceal haemorrhage, where the short history remains the only clue to ALF.

\section{Chronic liver failure}

CLF occurs on the background of established liver cirrhosis. The typical clinical features include jaundice, ascites, encephalopathy, sarcopenia along with laboratory features, such as hypoalbuminaemia and coagulopathy, often associated with a rising creatinine and hyponatraemia as liver disease advances. Box 1 describes common causes of CLF. ${ }^{12}$

\section{Acute on chronic liver failure}

Acute-on-chronic liver failure (AoCLF) is a syndrome characterised by acute decompensation of CLD associated with organ failures and high short-term mortality. Sepsis, active alcoholism and relapse of chronic viral hepatitis are the most common reported precipitating factors, but still only account for perhaps half the cases, the remainder have no identifiable trigger. The poor prognosis mimics that seen in ALF and mandates an expedited triage and consideration for LT. However, while LT remains the definitive treatment, sadly very few prove suitable. $^{13}$

\section{When to consider referral/discussion with the LTU in CLF or AoCLF}

Liver transplantation should be considered, when a patient with established liver disease develops any of the typical features of decompensation (figure 1). As decompensation correlates with rising morbidity and mortality, the supervising clinician should reflect on the key considerations outlined below.

\section{Box 1 Causes of chronic liver failure (CLF)}

Causes of CLF:

$\rightarrow$ Alcohol.*

- Non-alcoholic fatty liver disease.

- Chronic viral hepatitis (B, C and D).

- Autoimmune liver disease (Primary Biliary Cholangitis, Primary Sclerosing Cholangitis, Autoimmune Hepatitis and overlap syndromes).

- Wilson's disease.

- Genetic haemochromatosis.

- Alpha-1 antitrypsin deficiency.

- Secondary sclerosing cholangitis.

- Congenital hepatic fibrosis and other congenital or hereditary liver diseases.

*Alcoholic hepatitis tends to present acutely, frequently with no history of liver disease. Most patients recover with abstinence, but recent studies have demonstrated excellent outcomes with liver transplant in highly selected patients. ${ }^{44} 45$ 


\begin{tabular}{|c|c|}
\hline 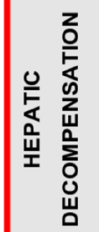 & $\begin{array}{l}\text { Jaundice } \\
\text { Ascites } \\
\text { Variceal haemorrhage } \\
\text { Hepatic encephalopathy }\end{array}$ \\
\hline
\end{tabular}

Figure 1 Clinical features of hepatic decompensation.

Key considerations in patients with hepatic decompensation

1. Is the decompensation potentially reversible (for example with abstinence in the case of ALD or with anti-virals in untreated chronic viral hepatitis)* or

2. If not reversible, is the patient suitable for $\mathrm{LT}^{*}$ ? or

3. Are there any contraindications to LT such as comorbidity which preclude transplant* (see table 5) or

4. If not currently suitable for transplant, could a patient become suitable with treatment or an intervention*?

*If in any doubt, seek advice from local LTU

Bear in mind that it is possible for a patient to be too unwell for LT if the referral is made too late.

To aid with the assessment of suitability for referral, the UK Model for End-Stage Liver Disease (UKELD) score can be calculated. The UKELD score is devised from patient's INR, serum sodium, creatinine and bilirubin (https://www.odt.nhs.uk/transplantation/ tools-policies-and-guidance/calculators/). ${ }^{14}$ UKELD scores $\geq 49$ indicate survival advantage for LT over conservative management in patients with irreversible decompensation.
Patients with decompensated CLD, unsuitable for LT, should have this conclusion documented and receive symptom-directed care.

Non-liver failure indications for liver transplantation Some patients will still benefit from LT, even though their liver is not failing (i.e, likely to cause death within 12 months). This would include patients with cirrhosis and a UKELD score under 49, such as PBC patients with intractable pruritus (see table 2). 56815

\section{HOW TO REFER FOR LT}

The next step is referral to the nearest LTU (see online supplementary appendix 1). For ALF patients, a telephone referral is obligatory, but for all other indications, a written referral suffices. Email may speed the referral process, but correspondence with a named individual in LTU encourages collaborative dialogue between referring and transplant physicians. Most referrals for CLD patients come from secondary care hepatologists or gastroenterologists, but referrals are welcomed from any source in primary or secondary care.

\section{What will the LTU want to know?}

The LTU will require details of the primary liver disease and its complications, comorbidity, compliance issues, alcohol or drug misuse, family support, previous abdominal surgery and cancer.

A sample transplant assessment tool used is attached as online supplementary appendix 2, but shouldn't replace a letter covering the above issues.

Table 2 Other aetiologies (non-liver failure) suitable for $\mathrm{LT}^{56815}$

\begin{tabular}{ll}
\hline Variant syndromes* & Hepatocellular carcinoma (HCC) $\dagger$ \\
\hline Hepatopulmonary syndrome & Up to $25 \%$ of liver transplants in UK have HCC \\
Persistent and intractable pruritus & Associated with most CLD (HBV, HCV, ALD, NAFLD, autoimmune liver \\
disease, haemochromatosis) and Aflatoxin ingestion
\end{tabular}

*A variant syndrome is a patient with chronic liver disease whose UKELD score is $<49$.

tAll patients with HCC should be managed within a Liver cancer MDT, which would be expected to recommend referral for liver transplantation as one of the potential 'outcomes'.

AFP, alpha foetoprotein; ALD, alcoholic liver disease; CLD, chronic liver disease; HBV, hepatitis B virus; HCV, hepatitis C virus; NAFLD, non alcoholic fatty liver disease; PCWP, pulmonary capillary wedge pressure; PVR, pulmonary vascular resistance. 
Table 3 Local investigations and key information to include in referral letter (more details in online supplementary appendices 3-5)

\begin{tabular}{lll}
\hline $\begin{array}{l}\text { Comorbidity } \\
\text { (include all details of pathologies, } \\
\text { and important negatives) }\end{array}$ & $\begin{array}{l}\text { Investigations } \\
\text { (general investigations as below) }\end{array}$ & Disease-specific investigations \\
\hline $\begin{array}{l}\text { Cardiovascular } \\
\text { Respiratory }\end{array}$ & Chest X-ray & PSC: colonoscopy and recent liver imaging \\
Renal & Echocardiogram & PBC/AIH: drug history \\
\hline Bone & Oxygen Saturation & Hepatitis B: screening tests and viral load \\
\hline HIV & Analysis of Ascites & Hepatitis C: details of treatment \\
\hline Obesity & Endoscopy & HCC: recent imaging and MDT discussions \\
\hline Surgical/anaesthetic history & Nutritional assessment & PLD/PLKD: brain imaging for Berry aneurysms \\
Nutrition & Assessment of the performance status & Budd-Chiari syndrome: history of shunts. \\
\hline $\begin{array}{l}\text { Metabolic syndrome } \\
\text { Non-hepatic cancer }\end{array}$ & Up to date blood tests and UKELD & Encephalopathy: brain imaging, ammonia, number connection tests \\
\hline Infectious disease & Adherence/addiction & \\
\hline $\begin{array}{l}\text { Social support } \\
\text { Disabilities }\end{array}$ & & Ascites: number of drains, episodes of SBP \\
\hline Alcohol and substance abuse & Alcohol related liver disease: period of abstinence, engagement with \\
\hline Mental health & & addiction services and so on \\
\hline Smoking & & \\
\hline
\end{tabular}

AlH, Autoimmune Hepatitis; ArLD, Alcohol related Liver Disease; HCC, Hepatocellular Carcinoma; MDT, Multi Disciplinary Team; NG, Naso-gastric; NICE, National Institute for Health \& Care Excellence; PBC, Primary Biliary Cholangitis; PLD/PLKD, Polycystic Liver Disease/Polycystic Liver \& Kidney Disease; PSC, Primary Sclerosing Cholangitis; SBP, Spontaneous Bacterial Peritonitis; TC, Transplant Co-ordinator.

The quality and content of the referral can influence the pace of transplant assessment. This guide is not intended to be exhaustive, but ensures referrers provide critical information including; general investigations required prior to referral (online supplementary appendix 3); disease specific data required by LTU (online supplementary appendix 4) and comorbidities, psychosocial factors and addiction data that may inform the transplant assessment process (online supplementary appendix 5). All summarised in table 3 .

\section{Considerations in patients with alcohol and drug-use disorders \\ Alcohol}

Best practice suggests that patients benefit from early referral to, and engagement with, local addiction services. Repeated non-adherence with documented advice to abstain from alcohol is an absolute contraindication to LT, so all discussions regarding the requirement for lifelong abstinence must be documented and the patient informed of the implication.

The UK Liver Advisory Group ${ }^{16}$ and National Institute for Health and Clinical Care Excellence (NICE) ${ }^{17}$ have recently updated the policies relating to referral of alcohol related liver disease (ArLD) patients for consideration of LT.

Patients:

- Who are alcohol dependent and continue drinking (even at reduced levels) should not be referred. Referral to alcohol services and engagement is mandatory.

- Who, after 3 months of validated abstinence, still have an indication for liver transplant, should be referred. Validation of abstinence includes random blood alcohol levels, alcohol metabolite testing and support from addiction services. ${ }^{17}$

- Who are abstinent for $<3$ months, and positively engaged with addiction services, can be referred if there are issues (nutrition, frailty, etc) that might complicate the assessment, or death from liver disease may occur within 3 months.

Thus, there is no absolute rule governing the period of abstinence, other than patients must be abstinent at the time of referral. A pragmatic approach is to advise all patients with a failing liver due to alcohol, to become abstinent and engage with addiction services. If there is no immediate indication for referral for LT (as outlined in NICE guidance) then wait for 3 months to observe and if no improvement occurs, refer for LT. If, at 3 months, there is evidence of ongoing liver recovery, then a further 3-month deferment may optimise liver recovery, and also test the patient's commitment to abstinence. At 6 months of abstinence, little further recovery can be expected and referral for LT is appropriate for any patient who remains in liver failure.

Drug addiction/misuse

Drug testing is part of the assessment for such patients. The use of prescribed methadone or buprenorphine replacement therapy does not preclude assessment for LT. However, current use of non-prescribed controlled drugs, addictive medications or 'designer' alternatives precludes referral.

\section{LT ASSESSMENT}

On receipt of a referral, the LTU determines whether the assessment requires urgent transfer, elective 


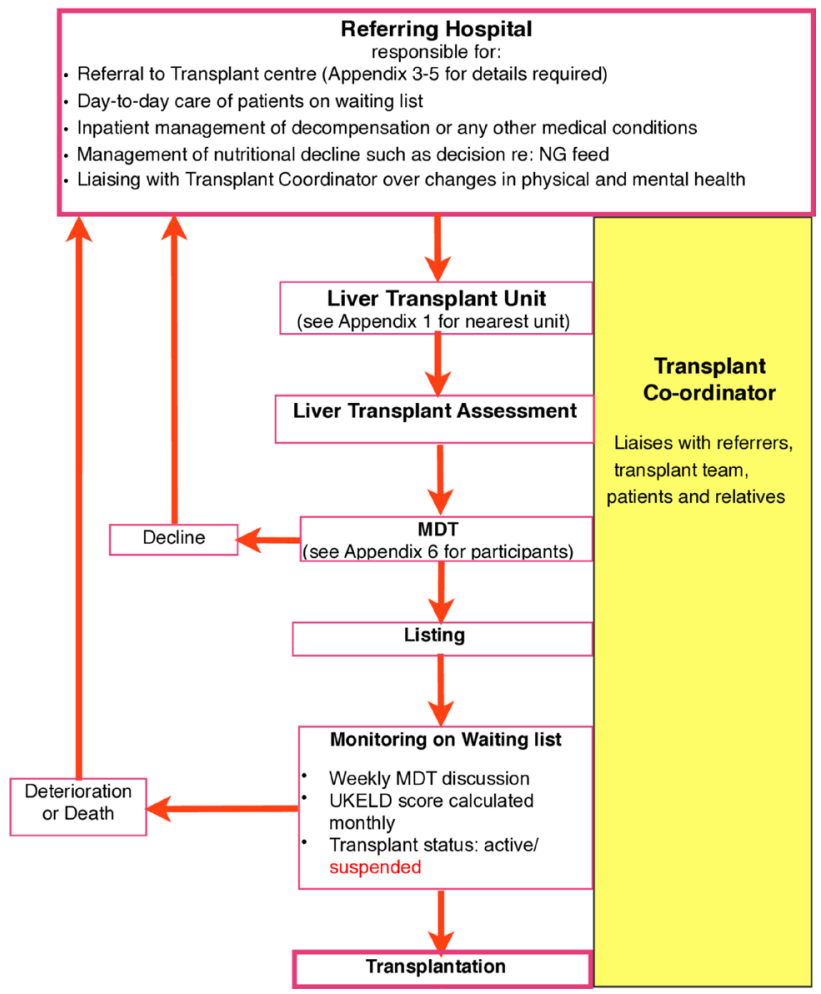

Figure 2 Flow diagram displaying the process of LT assessment from initial referral through workup and listing meeting, to monitoring on the list and either transplant/ death or suspension from the list. The roles and responsibilities of the local unit and the TC are shown. LT, liver transplant; MDT, multi-disciplinary team; NG, naso-gastric; TC, transplant coordinator; UKELD, UK Model for End-Stage Liver Disease

inpatient review, outpatient review or a combination approach. The referral-to-decision times of LTUs should be available for patients and referring hospitals (see figure 2). ${ }^{18}$

The aims of the liver transplant assessment are:

- To confirm the hepatological diagnosis.

- To confirm medical treatment has been optimised.

- To confirm that LT remains the most appropriate option.

- To evaluate mental and physical health comorbidities.

- To identify any contraindications.

- To ensure patients are fully informed of LT.

The transplant assessment is managed by the transplant coordinator (TC) and performed by the core MDT, consisting of physician, surgeon, anaesthetist, social worker, TC and dietician with additional input from pharmacist, addiction specialist, renal physician, oncologist and psychiatrist (see online supplementary appendix 6).

\section{Transplant coordinator}

The LT evaluation is supervised by the TC. ${ }^{19}$ The TC communicates directly with the patient and family/ support network. This relationship evolves over the assessment process and beyond, depending on progress (figure 2). The TC gains invaluable insight into the candidate.
Table 4 Absolute and relative contra-indications to LT

\begin{tabular}{|c|c|}
\hline Absolute contraindications & Relative contraindications* \\
\hline Untreated HIV* & Inadequate social support \\
\hline $\begin{array}{l}\text { Severe extrahepatic disease with } \\
\text { predicted mortality }>50 \% \text { at } 5 \text { years } \\
\text { including psychiatric disorder }\end{array}$ & Smoking \\
\hline Severe irreversible pulmonary disease & Certain anatomical variants \\
\hline Ongoing alcohol misuse & $\begin{array}{l}\text { Extensive previous abdominal } \\
\text { surgery }\end{array}$ \\
\hline Active illicit drug use & $\mathrm{BMI}>40 \mathrm{~kg} / \mathrm{m}^{2}$ \\
\hline Certain anatomic variants & $\begin{array}{l}\text { Poor clinic attendance and/or } \\
\text { adherence }\end{array}$ \\
\hline \multicolumn{2}{|l|}{ Ongoing extra-hepatic sepsis* } \\
\hline \multicolumn{2}{|l|}{$\begin{array}{l}\text { Active or previous extra-hepatic } \\
\text { malignancy } \dagger\end{array}$} \\
\hline \multicolumn{2}{|l|}{ Liver cancer outside criteria* } \\
\hline \multicolumn{2}{|c|}{$\begin{array}{l}\text { *These contra-indications can be temporary and require discussion with } \\
\text { LTU. } \\
\text { †LT is considered for patients with neuroendocrine tumours (requires } \\
\text { referral to national panel). }{ }^{46} \\
\text { BMI, body mass index; LT, liver transplant; LTU, liver transplant unit. }\end{array}$} \\
\hline
\end{tabular}

As up to $40 \%$ of assessments are declined, the TC's role includes advising and supporting such individuals, especially those who assumed referral automatically implied acceptance onto the waiting list. For patients accepted onto the waiting list, the TC communicates with patient's referring hospital, GP and community services. The TC provides an explanation of what patients can expect while waiting and when called in for LT.

\section{Indications for LT}

The transplant hepatologist confirms the primary liver condition (section 2), makes certain that medical treatment has been optimised, and ensures disease specific investigations are completed (see online supplementary appendices 3-5).

\section{Contraindications to LT}

Table 4 describes absolute and relative contraindications to LT.

\section{Conclusion of transplant assessment MDT decisions}

Following assessment, candidates are discussed at the MDT meeting with three potential outcomes: decline, defer, or accept. For those declined, the option of a second opinion, from another transplanting centre, is discussed with the patient and carers either by the hepatologist or the TC. Responsibility for such a further referral rests with the patient's local physician or GP.

Some patients require further optimisation such as nutritional or cardio-respiratory input, prior to activation on the waiting list. Such 'deferred' patients require re-discussion, once the additional elements are addressed. 
The remainder of assessments will be 'accepted' and placed on the LT waiting list. The option of live donation will be discussed, if appropriate.

\section{Consent for LT}

Consent for LT for candidates who retain mental capacity includes the general guidance for individuals undergoing any clinical intervention (see www.gmc-uk. org). However, the nature and risks of solid organ transplantation, means the process is more complex. Fuller guidance is given by the British Transplantation Society and National Health Service Blood and Transplant (https://bts.org.uk/wpcontent/uploads/2016/09/12 BTS_NHS_Consent_April_2013-1.pdf). LTU's provide oral and written information concerning the risks and benefits of LT for patients and their carers, incorporating outcomes, donor organ related risks (infective, malignant, autoimmune, metabolic and others), procedure risks, disease recurrence and the need for adherence and life-long follow-up. The right to decline certain organs is carefully discussed (see Part 2, figure 1).

\section{HOW TO MANAGE THE PATIENT ON THE WAITING LIST \\ Waiting list}

During 2015-2016, 1161 patients joined the LT waiting list in the UK. At 1-year post-registration, 73\% of patients had received a LT, 9\% had died waiting or been removed due to deterioration. A further $4 \%$ were removed for other reasons such as clinical improvement, non-compliance or at patient's request. The remaining $14 \%$ were still waiting. ${ }^{3}$

The waiting times depend on several factors, including recipient blood group, size and illness severity (i.e. UKELD score). The median waiting time is currently 135 days, though this is shorter for recipients who are blood group $\mathrm{AB}$ (56 days), A (84 days) and B (129 days) than blood group O (256 days). ${ }^{3}$ Details of organ allocation are outlined in Part 2.

\section{Monitoring on the waiting list}

Patients listed for LT must be monitored closely for changes in their clinical circumstances. The 'local' team manage all the patient's routine care, but as this may impact on their suitability for LT, regular and careful communication with the LTU, via the TC is essential (see figure 2).

\section{Optimisation of patients on the waiting list Managing deterioration}

Patients on the LT waiting list frequently present with decompensation to their referring hospital. This decompensation carries a significant mortality risk. ${ }^{20}$

The Lancet Standing Commission on Liver Disease has highlighted the need to focus on improving the care for acutely ill, hospitalised patients with liver disease. ${ }^{21}$ Ideally, hospitals should have in place a 'care bundle' for patients admitted with decompensated cirrhosis. ${ }^{22}$
Management of listed patients in the referring hospital

Patients on LT waiting list require monthly review in gastroenterology/hepatology outpatient clinics for nutritional review, blood-sampling, UKELD calculation and surveillance tests for cirrhosis. The LTU should be appraised of any deterioration, as listing status may need reviewing. Transfer to the LTU for acute deterioration is sometimes necessary, but if not, the confidence of patients and their carers is enhanced when there is open dialogue between the local hospital and the LTU.

\section{Nutrition}

Most patients with end-stage cirrhosis are malnourished ${ }^{23}$ and malnutrition in recipients predicts poorer outcome after LT. $^{2425}$ LTUs recommend a nutritional supplement for patients on the waiting list for the beneficial effect on anthropomorphic indices. ${ }^{26}$ Obesity is increasingly common among patients on the waiting list for LT. Sarcopenic obesity, or severe muscle depletion in the setting of obesity, is reported in almost half of obese patients with cirrhosis and is associated with an increased risk of pre-LT mortality. For patients with compensated cirrhosis, traditional lifestyle modifications are safe, but very low calorie diets $(<1000$ calories/day) are not safe. For decompensated cirrhotics, low-calorie diets may exacerbate sarcopenia and malnutrition, so such patients should maintain caloric intake with higher protein, nutrient-rich foods. ${ }^{27}$

\section{Exercise}

There is little data on exercise in patients waiting for LT. However, exercise programmes known as 'prehabilitation' can improve functional capacity and postoperative outcomes in patients with liver disease awaiting major surgery. ${ }^{28}$ Recently, the Birmingham group published a proposal to clarify this issue in patients awaiting $\mathrm{LT}^{29}$ Most centres advise a sustained exercise target of up to 25 minutes daily, depending on the individual patients pre-existing activity levels and physical impairments. A step-counter (available as an app) is helpful for target setting and the Birmingham team's proposal also incorporates specific advice on functional resistance exercise training that can readily be carried out at home. ${ }^{29}$

Other lifestyle factors

Lifestyle factors are central to survival both on the waiting list and beyond. Patients should be supported to make positive and sustainable lifestyle behaviour changes.

Active engagement with alcohol services is key for any ArLD patient and this may be a condition for listing. Alcohol use rates of $15 \%-25 \%$ have been reported for patients on LT waiting lists so ongoing monitoring (blood, urine, breath or hair) and support are essential. ${ }^{30}$ Most centres require random testing 
for patients listed for ArLD and will liaise with the local hospital to facilitate timing and frequency.

Active smoking increases all-cause mortality at 5 and 10 years after LT $^{31}$ due to additional surgical complications, more cardiovascular disease, sepsis and solid-organ malignancy. ${ }^{31-34}$ Smokers must engage in a smoking cessation programme and if smoking cessation is a condition for listing, patients should expect carbon monoxide breath-testing.

\section{Psychosocial support}

Patients listed for LT have high rates of psychological distress and depression which reduces quality of life, adaptive coping and functional status. ${ }^{35}$ Significant depression reduces pretransplant survival. ${ }^{36}$ Waiting times, concern about deterioration, organ scarcity and false-alarms contribute to patient anxiety. All patients require screening for depression and management accordingly.

Patients and carers receive education, including attendance at patient information sessions at the time of listing. This should include access to 'expert patients', information on LT services, the patient pathway, support groups and services offering psychological, social and spiritual/cultural support. The LTU have a transplant healthcare professional available 24/7 for telephone advice for patients and carers and ongoing contact with TC, specialist nurses and a social worker, as necessary.

\section{PALLIATIVE CARE AND LT}

Liver transplantation is the gold standard treatment for many patients with ALF, CLF and liver cancer, however, almost half of those assessed are declined and $20 \%$ patients die while waiting, meaning four people die for every one transplanted. Patients with CLD have a variable level of access to palliative care services, which can vary in quality. ${ }^{37} 38$

By definition, those listed for LT have advanced disease and therefore, concomitant physical and psychosocial issues. Patients suffer from a high physical symptom burden ${ }^{39}{ }^{40}$; symptoms are often complex and dramatic, frequently necessitating hospital admission ${ }^{41}$ with a poor evidence base to support the use of many drugs. Patients also suffer

\section{Key points}

- Consider all patients with decompensated CLD for liver transplantation

- Discuss all ALF patients with LTU

- Provide LTU with details of primary liver disease and comorbidities in mental \& physical health

- Patients on transplant waiting list are the shared responsibility of referrer and LTU

- The palliative care needs of the patient are a critical part of the transplant assessment process. complex psychosocial issues including the stigma of liver disease, complex socioeconomic background circumstances and uncertainty associated with the potential for re-compensation and the possibility of transplantation.

Maintaining hope while ensuring an appropriate holistic assessment of the patient's needs is challenging for everyone involved in delivering care. Discussions on end-of-life care including preferences, is an essential component in the management of patients with advanced liver disease, including those awaiting LT.

Early palliative care intervention can improve quality of life by improving symptom burden and mood, alongside less aggressive treatment and a reduction in hospitalisation. ${ }^{42} 43$ An assessment of palliative care needs should form an integral part of any transplant assessment process. Collaborative working is essential at a time of such great uncertainty if the overall quality of life for these patients and their carers is to be improved.

\section{CONCLUSIONS}

- All patients with decompensated CLD, should be considered for LT.

- All ALF patients should be discussed with the LTU and transferred in timely fashion, if appropriate.

- LT may be considered for variant syndromes, HCC and various other non-liver failure indications after discussion with LT team.

- The LTU require details of diagnosis, comorbidity, nutritional status and frailty in order to complete evaluation.

- Patients on the LT waiting list are shared between the referring centre and LTU. Good communication between the various healthcare professionals is critical. For patients who deteriorate, candid discussions with individuals and their relatives coupled with timely utilisation of palliative care services should optimise outcome for all concerned.

\section{Author affiliations}

'Department of Hepatology, York Teaching Hospitals NHS Foundation Trust, York, UK

${ }^{2}$ Pharmacy department, King's College Hospital NHS Foundation Trust, London, UK

${ }^{3}$ South West Liver Unit, Plymouth Hospitals NHS Trust, Plymouth, UK

${ }^{4}$ Liver Unit, University Hospitals Birmingham NHS Foundation Trust,

Birmingham, UK

${ }^{5}$ Department of Cellular Pathology, University of Birmingham, Birmingham, UK ${ }^{6}$ Department of Hepatology, York Teaching Hospitals NHS Foundation Trust, York, UK

${ }^{7}$ Liver Transplantation Service, Leeds Teaching Hospitals NHS Trust, Leeds, UK

${ }^{8}$ Department of Hepatology, Cambridge University Hospitals NHS Foundation

Trust, Cambridge, UK

${ }^{9}$ Liver Unit, The Newcastle Upon Tyne Hospitals NHS Foundation Trust, Newcastle upon Tyne, UK

${ }^{10}$ Liver Transplantation \& HPB Surgery, King's College Hospital NHS Foundation Trust, London, UK

${ }^{11}$ Liver Transplantation \& HPB surgery, University Hospitals Birmingham NHS Foundation Trust, Birmingham, UK

${ }^{12}$ Liver Unit, University Hospitals Birmingham NHS Foundation Trust, Birmingham, UK 
${ }^{13}$ Liver Transplantation \& HPB Surgery, Leeds Teaching Hospitals NHS Trust, Leeds, UK

${ }^{14}$ Pharmacy department, York Teaching Hospitals NHS Foundation Trust, York, UK

${ }^{15}$ Palliative Care Medicine, King's College Hospital NHS Foundation Trust, London, UK

${ }^{16}$ Liver Transplantation Service, Royal Free London NHS Foundation Trust, London, UK

${ }^{17}$ Scottish Liver Transplant Unit, Royal Infirmary of Edinburgh, Edinburgh, UK ${ }^{18}$ Department of Hepatology, Royal Free London NHS Foundation Trust, London, UK

${ }^{19}$ Department of Hepatology, Royal Free London NHS Foundation Trust, London, UK

${ }^{20}$ Liver Unit, University Hospitals Birmingham NHS Foundation Trust, Birmingham, UK

Acknowledgements Two individuals, Ms Lorna Tong and Mrs Elizabeth Crawshaw, read the manuscripts and offered critique as 'expert patients' and the authors are grateful for their critical input. The authors are thankful to Ms Robyn Southeran from the Medical Illustration department at York Hospital NHS FT.

Contributors There were 20 authors involved in the production of these two articles concerning liver transplantation. The original project was divided into an introduction, nine sections and a conclusion. From that original outline, the sections were written by writing groups and then collated. The nine sections were then divided into two halves for the purposes of publication, after discussion with the editor of FG. Each contributor provided editing input, to the project, as the manuscript went through its many iterations. The specific contribution/participation of each contributor are as follows: $\mathrm{CM}$ (consultant hepatologist in a DGH): senior author. Initiated section divisions, collected manuscripts. Contributed to writing by adding DGH aspects to all part 1 and management of post-transplant patient section. Edited all tables and oversaw the process. CM is responsible for overall content as guarantor. A Considine is a consultant pharmacist. She co-wrote the section on the Immunosuppression agents in Part 2 with Prof Neuberger and gave input into Part 1 particularly with the 'disease specific considerations' and where medication interactions can occur. MC (consultant transplant hepatologist): Co-authored the section on 'Management of the patient on the waiting list' and then read both Part 1 and 2 of final submission as an additional critique for all sections. Critical role in planning and acquisition of data for inclusion into guideline, along with evaluation of relevance to project. Final manuscript editing and approval. $\mathrm{AH}$ (consultant transplant hepatologist): Co-authored the section on 'How to refer', and then drew up the tables and added valuable additional input, as well as re-write participation for the sections, when the original submission was too lengthy. Critical role in planning, final manuscript editing and approval. $\mathrm{SH}$ is a consultant histopathologist and wrote the section on cellular rejection in Part 2. He added valuable oversight in Part 1, particularly as both parts were too lengthy and required significant reduction in word count. JH (consultant hepatologist in a DGH) wrote the section on Transplant assessment and with KJ refined this section, to focus on the DGH referrer. JH also read both completed parts to provide the DGH perspective on these elements of liver transplantation and ensure focus was correct for that audience. Critical role in planning and acquisition of data for inclusion into Part 1 of guideline, along with evaluation of relevance to project. Part 1 and 2 final manuscript editing and approval. KJ (Transplant co-ordinator) provided section on the Transplant co-ordinator and then gave critical input for aspects on process of organ selection along with RP (below). Critical role in planning and acquisition of data for inclusion into guideline, along with evaluation of relevance to project. Final manuscript editing and approval JL (consultant transplant hepatologist) coauthored the section on 'How to refer' and provided editorial input for part 2. Critical role in planning and acquisition of data for inclusion into guideline, along with evaluation of relevance to project. Final manuscript editing and approval SM (consultant transplant hepatologist) co-authored the section on 'How to manage the patient on the waiting list' bringing together the co-ordinators input with the transplant centre and the interaction with secondary care referring centre. Providing insights from both sides of the secondary/tertiary care interaction and then editing the initial contribution of the section to a more manageable section. Ensuring relevance of data collected for the project along with final manuscript editing and approval KM (consultant transplant surgeon) contributed to the section in part 2 on Transplant surgery and outcomes. KM also provided input in Part 1 into section on Transplant assessment and previous surgery. Critical role in planning and acquisition of data for inclusion into guideline, along with evaluation of relevance to project. Final manuscript editing and approval DM (consultant transplant surgeon) co-authored the section on Transplant surgery with KM and post-transplant surgical complications. He also provided input in Part 1 into section on Transplant assessment and previous surgery. Critical role in planning and acquisition of data for inclusion into guideline, along with evaluation of relevance to project. Final manuscript editing and approval JN (consultant transplant hepatologist) wrote the section on Post-Transplant Immunosuppression with the aid of A Considine. Prof

Neuberger also contributed to the Part 1 in editorial role, when he helped with the original concept, he provided a critical role following the original guideline production and prior to it's splitting into two halves (Part 1 and 2) and ensuring correct focus was maintained when the manuscript was reduced in size. RP (consultant transplant surgeon) wrote the section on organ allocation and donation. He also made a significant contribution to the post-operative care and complications sections and the pre-op evaluation (Part 1). Critical role in planning and acquisition of data for inclusion into guideline, along with evaluation of relevance to project. Final manuscript editing and approval AP (Liver Pharmacist) contributed to Part 2 immunosuppression section, but also gave useful input into Part 1 and 2 from point of view of medication and drug interactions, particularly with viral hepatitis treatment. Critical role in evaluating data for inclusion into guideline, along with maintain relevance to project. Final manuscript editing and approval WP (Consultant in Palliative Care) authored the section on Palliative Care and Transplantation in Part 1. Her contribution in Part 2 was proof-reading and providing critical input. Critical role in planning and acquisition of data for inclusion into guideline, along with evaluation of relevance to project. Final manuscript editing and approval LS is a Transplant co-ordinator. She contributed to the section on How to refer a patient for liver transplant (Part 1) and gave input into section on Organ allocation (Part 2). Critical role in planning and acquisition of data for inclusion into guideline, along with evaluation of relevance to project. Final manuscript editing and approval KS (consultant transplant hepatologist) wrote the section on 'When to refer' in Part 1, but also gave significant editorial input to entire project, at the time of the section merge and subsequent division into two halves. Critical role in planning and acquisition of data for inclusion into guideline, along with evaluation of relevance to project. Final manuscript editing and approval DT and RW (consultant transplant hepatologists) co-authored the section on Transplant outcomes. They provided critical input into Part 1 as well, with respect to referral process. Critical role in planning and acquisition of data for inclusion into guideline, along with evaluation of relevance to project. Final manuscript editing and approval. DT (consultant transplant hepatologist) co-authored the section on Postoperative care and complications (nonsurgical). DT also supported the entire process by helping the lead author with editing sections and discussion of tables, pictures, deciding on section inclusion, data relevance and final manuscript editing and approval.

Funding The authors have not declared a specific grant for this research from any funding agency in the public, commercial or not-for-profit sectors.

Competing interests None declared.

Patient consent for publication Not required.

Provenance and peer review Not commissioned; externally peer reviewed. 
Open access This is an open access article distributed in accordance with the Creative Commons Attribution Non Commercial (CC BY-NC 4.0) license, which permits others to distribute, remix, adapt, build upon this work noncommercially, and license their derivative works on different terms, provided the original work is properly cited, appropriate credit is given, any changes made indicated, and the use is noncommercial. See: http://creativecommons.org/licenses/by-nc/4. $0 /$.

\section{ORCID iD}

Charles Millson http://orcid.org/0000-0001-6989-9497

\section{REFERENCES}

1 Calne RY. Transplantation of the liver. Ann Surg 1978;188:129-38.

2 Neuberger J. Liver transplantation in the United Kingdom. Liver Transpl 2016;22:1129-35.

3 NHS Blood and Transplant. Annual report on liver transplantation 2015/2016.

4 Devlin J, O'Grady J. Indications for referral and assessment in adultliver transplantation: a clinical guideline. Gut 1999;45:vi1-22.

5 BASL. Guidelines on referral for liver transplant assessment, 2012. Available: http://odt.nhs.uk/pdf/advisory_group_papers/ LAG/referral_for_transplantation.pdf

6 European Association for the Study of the Liver. Electronic address: easloffice@easloffice.eu. EASL clinical practice guidelines: liver transplantation. J Hepatol 2016;64:433-85.

7 Wendon, J, Cordoba J, Dhawan A, et al. EASL clinical practical guidelines on the management of acute (fulminant) liver failure. J Hepatol 2017;66:1047-81.

8 Martin P, DiMartini A, Feng S, et al. Evaluation for liver transplantation in adults: 2013 practice guideline by the American association for the study of liver diseases and the American Society of transplantation. Hepatology 2014;59:1144-65.

9 European liver transplant registry. Available: http://www.eltr. org

10 Khan R, Koppe S. Modern management of acute liver failure. Gastroenterol Clin North Am 2018;47:313-26.

11 Blackmore L, Bernal W. Acute liver failure. Clin Med 2015;15:468-72.

12 EASL practice guidelines for the management of patient with decompensated cirrhosis. Journal of Hepatology. In Press.

13 Jalan R, Moreau R, Kamath PS, et al. Acute-On-Chronic liver failure: a distinct clinical condition. Seminars in Liver Disease 2016;36:107-8.

14 UKELD. Calculator. Available: https://nhsbtdbe.blob.core. windows.net/ umbraco-assets-corp/./ukeld_calculator-2.xls

15 Sapisochin G, Bruix J. Liver transplantation for hepatocellular carcinoma: outcomes and novel surgical approaches. Nat Rev Gastroenterol Hepatol 2017;14:203-17.

16 . Available: http://odt.nhs.uk/pdf/liver_selection_policy.pdf

17 Clinical guideline [CG115]. Nice guidance: Alcohol-use disorders: diagnosis, assessment and management of harmful drinking and alcohol dependence. Available: http://www.nice. org.uk/guidance/cg115

18 Mathur AK, Talwalkar J. Quality measurement and improvement in liver transplantation. J Hepatol 2018;68:1300-10.

19 . Available: https://www.odt.nhs.uk/odt-structures-andstandards/organ-donation-retrieval-and-transplantation-teams/ role-of-transplant-recipient-co-ordinator/

20 Moreau R, Jalan R, Gines P, et al. CANONIC study Investigators of the EASL-CLIF Consortium. acute-on-chronic liver failure is a distinct syndrome that develops in patients with acute decompensation of cirrhosis. Gastroenterology 2013;144:1426-3.
21 Williams R, Aspinall R, Bellis M, et al. Addressing liver disease in the UK: a blueprint for attaining excellence in health care and reducing premature mortality from lifestyle issues of excess consumption of alcohol, obesity, and viral hepatitis. Lancet 2014;384:1953-97.

22 McPherson S, Dyson J, Austin A, et al. Response to the NCEPOD report: development of a care bundle for patients admitted with decompensated cirrhosis-the first $24 \mathrm{~h}$. Frontline Gastroenterol 2016;7:16-23.

23 O'Brien A, Williams R. Nutrition in end-stage liver disease: principles and practice. Gastroenterology 2008;134:1729-40.

24 Merli M, Giusto M, Gentili F, et al. Nutritional status: its influence on the outcome of patients undergoing liver transplantation. Liver Int 2010;30:208-14.

25 Le Cornu KA, McKiernan FJ, Kapadia SA, et al. A prospective randomized study of preoperative nutritional supplementation in patients awaiting elective orthotopic liver transplantation. Transplantation 2000;69:1364-9.

26 Tsien CD, McCullough AJ, Dasarathy S. Late evening snack: exploiting a period of anabolic opportunity in cirrhosis. $J$ Gastroenterol Hepatol 2012;27:430-41.

27 Spengler EK, O'Leary JG, Te HS, et al. Liver transplantation in the obese cirrhotic patient. Transplantation 2017;101:228896.

28 Dunne DFJ, Jack S, Jones RP, et al. Randomized clinical trial of prehabilitation before planned liver resection. British Journal of Surgery 2016;103:504-12.

29 Williams FR, Vallance A, Faulkner T. Home-Based exercise therapy in patients awaiting liver transplantation: protocol for an observational feasibility trial. BMJ Open 2018;8:e019298.

30 Erim Y, Böttcher M, Dahmen U, et al. Urinary ethyl glucuronide testing detects alcohol consumption in alcoholic liver disease patients awaiting liver transplantation. Liver Transplantation 2007;13:757-61.

31 Leithead JA, Ferguson JW, Hayes PC. Smoking-Related morbidity and mortality following liver transplantation. Liver Transplantation 2008;14:1159-64.

32 Herrero JI, Pardo F, D'Avola D, et al. Risk factors of lung, head and neck, esophageal, and kidney and urinary tract carcinomas after liver transplantation: the effect of smoking withdrawal. Liver Transplantation 2011;17:402-8.

33 Pungpapong S, Manzarbeitia C, Ortiz J. Cigarette smoking is associated with an increased incidence of vascular complications after liver transplantation. Liver Transplantation 2002;8:582-7.

34 Mathur AK, Ranney DN, Patel SP, et al. The effect of smoking on biliary complications following liver transplantation. Transplant International 2011;24:58-66.

35 De Bona M, Ponton P, Ermani M, et al. The impact of liver disease and medical complications on quality of life and psychological distress before and after liver transplantation. $J$ Hepatol 2000;33:609-15.

36 DiMartini A, Amanda Dew M, Javed L, et al. Pretransplant psychiatric and medical comorbidity of alcoholic liver disease patients who received liver transplant. Psychosomatics 2004;45:517-23.

37 NHS Liver Care. Nhs atlas of variation in healthcare for people with liver disease. London, 2013.

38 NCEPOD report. Alcohol related liver disease: measuring the units, 2013.

39 Boyd K, Kimbell B, Murray S, et al. Living and dying well with end-stage liver disease: time for palliative care? Hepatology 2012;55:1650-1.

40 Hope AA, Morrison RS. Integrating palliative care with chronic liver disease care. J Palliat Care 2011;27:20-7.

41 Volk ML, Tocco RS, Bazick J, et al. Hospital readmissions among patients with decompensated cirrhosis. American Journal of Gastroenterology 2012;107:247-52. 


\section{LIVER}

42 Baumann AJ, Wheeler DS, James M, et al. Benefit of early palliative care intervention in end-stage liver disease patients awaiting liver transplantation. J Pain Symptom Manage 2015;50:882-6.

43 Walling AM, Asch SM, Lorenz KA, et al. Impact of consideration of transplantation on end-of-life care for patients during a terminal hospitalization. Transplantation Journal 2013;95:641-6.
44 Thursz M, Morgan TR. Treatment of severe alcoholic hepatitis. Gastroenterology 2016;150:1823-34.

45 Lee BP, Mehta N, Platt L, et al. Outcomes of early liver transplantation for patients with severe alcoholic hepatitis. Gastroenterology 2018;155:422-30.

46 Moris D, Tsilimigras DI, Ntanasis-Stathopoulos I, et al. Liver transplantation in patients with liver metastases from neuroendocrine tumors: A systematic review. Surgery 2017;162:525-36. 